\title{
Stimmungsbilder von der Langen Nacht der Museen am 16. März 2013
}

Zum neunten Mal beteiligte sich die Württembergische Landesbibliothek an der Langen Nacht der Museen mit einer bewährten Mischung aus Führungen, Präsentationen und stimmungsvoller Livemusik. Etwa 2.200 Besucher zog es in die Landesbibliothek. Wie im letzten Jahr war es gelungen, Eric Gauthier mit seiner 2001 gegründeten Band zu gewinnen, seit Jahren ein Garant für beste musikalische Unterhaltung. International inzwischen sehr erfolgreich, trat er in Stuttgart in den letzten Monaten immer seltener auf. Grund genug für viele, sich den Auftritt in der WLB nicht entgehen zu lassen und die einzigartige Mischung aus gefühlvollen Britpop-Balladen und fetziger Rockmusik mitzuerleben. Neben den allseits beliebten Magazinführungen, an denen wieder 270 Gäste teilnahmen, nutzten 85 Besucher die Führungen durch die Digitalisierungswerkstatt. Im Buchmuseum hatte das Stuttgarter Publikum Gelegenheit, sich einen Überblick über das vielfältige künstlerische Schaffen des Buchillustrators Gunter Böhmer zu verschaffen. Wer die Weltliteratur nicht nur illustrativ, sondern auch akustisch erleben mochte, lauschte im Hauptlesesaal den Lesungen von Ute Oelmann. Auch einen Blick in die nahe Zukunft der WLB ließen sich zahlreiche Gäste nicht entgehen. Im Vortragsraum konnte man sich einen weitreichenden Einblick in Planung und Konzept des Erweiterungsbaus verschaffen. Traditionell sorgten eine Sektbar sowie eine Biertheke nebst Brezeln und griechischen Speisen für das leibliche Wohl der Gäste. Zu danken ist der Württembergischen Bibliotheksgesellschaft, die durch ihre finanzielle Unterstützung zum Erfolg der "Langen Nacht" beigetragen hat.

Jörg Ennen 


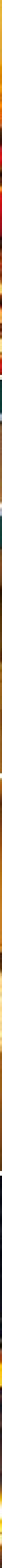

8

1

$A+2$

Bivin:
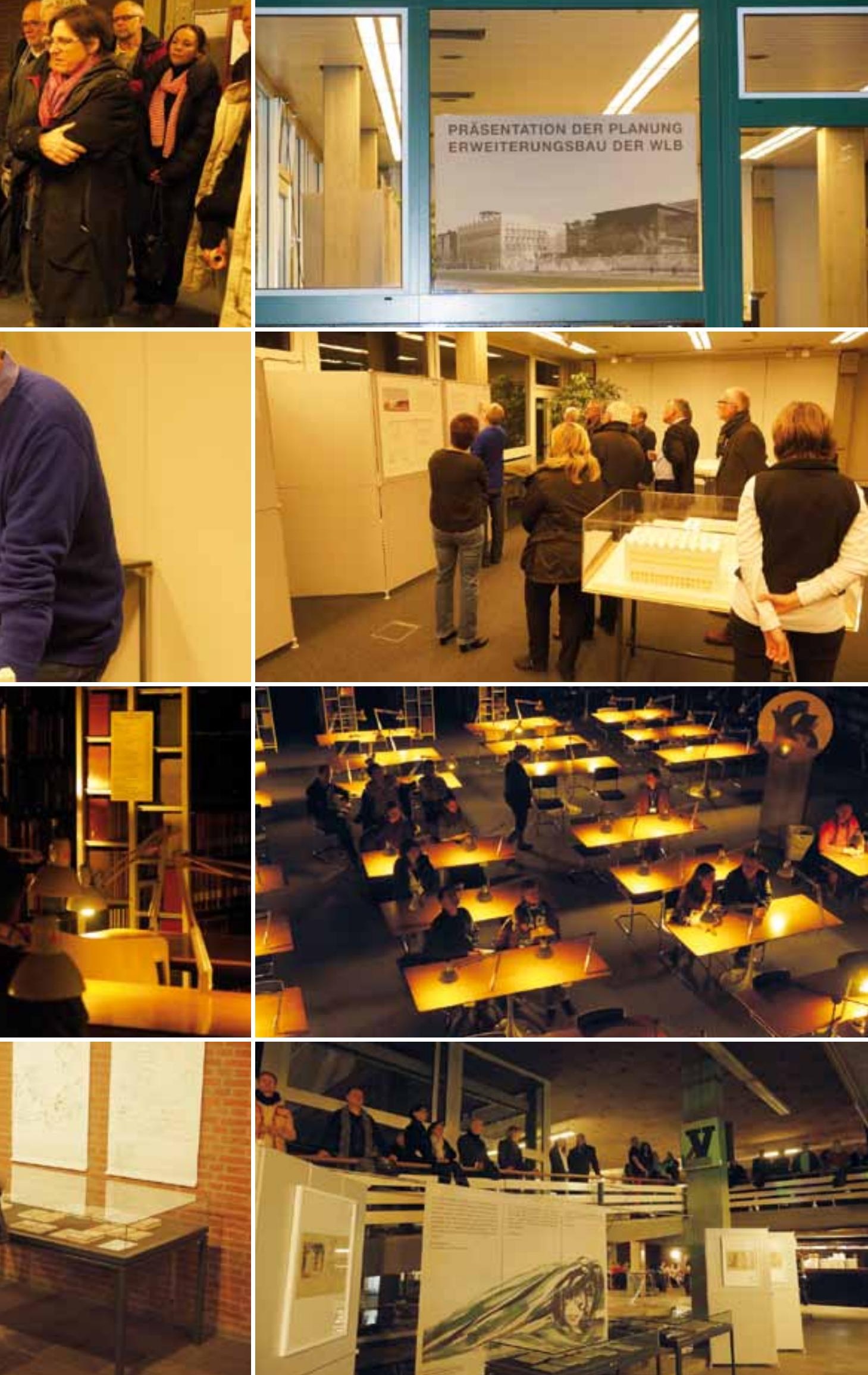


\section{Unterstützen Sie die Württembergische Landesbibliothek. Werden Sie Mitglied in der Württembergischen Bibliotheksgesellschaft!}

Die Württembergische Bibliotheksgesellschaft ist die Vereinigung von Förderern der Landesbibliothek, der sowohl Privatpersonen als auch renommierte Firmen angehören. Seit ihrer Gründung 1946 hat sie sich zum Ziel gesetzt, die Württembergische Landesbibliothek ideell und finanziell zu fördern. Die Schwerpunkte liegen darin, die Bibliothek bei der Erfüllung ihrer Aufgaben zu unterstützen, beim Erwerb von besonders hervorragenden Stücken finanzielle Hilfe zu leisten sowie die Öffentlichkeitsarbeit, besonders auch die Ausstellungen, zu fördern. Deshalb sind alle Freunde des alten und neuen Buches eingeladen, durch ihre Mitgliedschaft, den Erhalt und Ausbau der Sammlungen zu unterstützen.

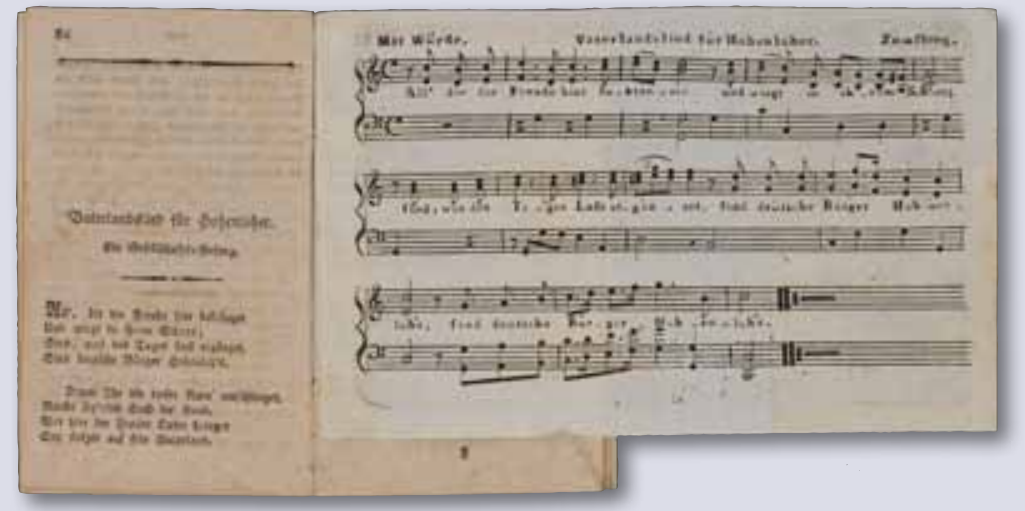

Zuwendung in 2012: Hohenloher Almanach 1803

\section{Ihre Vorteile als Mitglied}

- Sie werden regelmäßig über alle Veranstaltungen von Bibliothek und Gesellschaft informiert und erhalten persönliche Einladungen. Das Veranstaltungsangebot umfasst pro Jahr ca. zehn Vorträge, zwei bis drei Studienfahrten sowie Sonderführungen in der Bibliothek.

- Sie haben kostenlosen Zutritt zu allen Vorträgen.

- Sie erhalten die Gelegenheit, in Sonderführungen einen Blick hinter die Kulissen der Bibliothek zu werfen.

- Sie können zum Selbstkostenpreis an den Studienfahrten teilnehmen.

- Sie beziehen die Publikationen der Bibliotheksgesellschaft zu Sonderpreisen.

- Sie erhalten eine kostenlose Jahresgabe und ein Begrüßungsgeschenk.

\section{Jahresbeiträge}
40,- $€$ für Einzelpersonen
$10,-€$ pro weiteres Familienmitglied
250,- $€$ für Firmen und Gesellschaften
Spenden sind jederzeit willkommen.

\section{Kontakt:}

Christine Demmler

Konrad-Adenauer-Str. 8, 70173 Stuttgart

Tel. 0711 / 212-4428

Fax 0711 / 212-4422

E-Mail: wbg@wlb-stuttgart.de

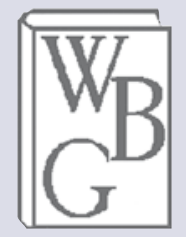

